\title{
Online statistics of Business \& Information Systems Engineering (BISE) / WIRTSCHAFTSINFORMATIK
}

\section{The Author}

Prof. Dr. Hans Ulrich Buhl $(\bowtie)$

FIM Research Center Finance \&

Information Management

University of Augsburg

Universitätsstraße 12

86159 Augsburg

Germany

hans-ulrich.buhl@

wiwi.uni-augsburg.de

Published online: 2010-06-24

This article is also available in German in print and via http://www. wirtschaftsinformatik.de: Buhl HU (2010) Online-Statistiken der WIRTSCHAFTSINFORMATIK / Business \& Information Systems Engineering (BISE) WIRTSCHAFTSINFORMATIK. doi: 10.1007/s11576-010-0227-1.

(C) Gabler Verlag 2010

\section{DOI 10.1007/s12599-010-0108-6}

BISE and WIRTSCHAFTSINFORMATIK are also available via http://www.bise-journal. org and http://www.wirtschaftsinformatik.de, respectively. Additionally, all articles published in BISE since 2009 and all articles published in WIRTSCHAFTSINFORMATIK since 2006 can be obtained via SpringerLink. This implies that all members of institutions with an appropriate licensing have access to our articles worldwide. In most countries, this also includes nearly all universities (and therefore all university employees and students).Thus, interested readers from all over the world are able to read articles published in BISE and WIRTSCHAFTSINFORMATIK.

Regarding the international market penetration we can record first successes over the last years: In 2009, the number of downloads conducted via SpringerLink stood at 37,493 for WIRTSCHAFTSINFORMATIK and - for a journal only started in 2009 a really exceptional figure - at 6,336 for BISE.

In the first quarter of 2010 WIRTSCHAFTSINFORMATIK's downloads increased up to $9,900(+28 \%$ compared to the corresponding quarter of the previous year) after having gone up approx. $745 \%$ to a very high level within the two years from 2007 to 2009. For the English-language new BISE, downloads conducted via SpringerLink nearly exploded within the first quarter of 2010 with an increase of more than $600 \%$ compared to the corresponding quarter of the previous year - thus within one year reaching 4,169 downloads. At the beginning of its second year BISE exceeded $40 \%$ of WIRTSCHAFTSINFORMATIK's - also very good - value with its 50 years of tradition.

Thus WIRTSCHAFTSINFORMATIK is further expanding its lead over other - much more broadly positioned - scholarly journals within the German-language area. And the internationalization strategy with BISE, more than a third of which was obtained already in its first year by the Asian-Pacific area, has experienced a better start than our greatest optimists could have imagined.

Taken together, both journals already hold - again measured in downloads - the third position worldwide of all IS-journals available via SpringerLink.

On this occasion I would like to thank all authors, reviewers, and readers. Besides our authors' achievements I would particularly like to highlight the work of the reviewers who assure - usually keeping very short review cycles - that we obtain and present scientific findings at a constantly high quality level, working in close cooperation with our authors mostly in several iterations. Above all however, I thank you, dear readers, for contributing to such an extent to our journal's increasing success.

Prof. Dr. Hans Ulrich Buhl Editor-in-Chief 